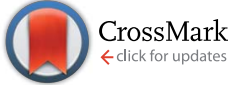

Cite this: RSC Adv., 2016, 6, 67976
Received 5th May 2016 Accepted 8th July 2016

DOI: 10.1039/c6ra11738d

www.rsc.org/advances

\section{Modified structure of two-dimensional polythiophene derivatives by incorporating electron-deficient units into terthiophene-vinylene conjugated side chains and the polymer backbone: synthesis, optoelectronic and self-assembly properties, and photovoltaic application $\uparrow$}

\author{
Chuen-Yo Hsiow, ${ }^{\star a b}$ Yu-Hsiang Lin, ${ }^{c}$ Rathinam Raja, ${ }^{a}$ Syang-Peng Rwei, ${ }^{c}$ \\ Wen-Yen Chiu, ${ }^{d}$ Chi-An Dai ${ }^{d}$ and Leeyih Wang ${ }^{\star a}$
}

\begin{abstract}
Molecular engineering on the conjugated side chains of two-dimensional (2D) conjugated polymers was conducted and its effect on the optical, electronic, self-assembly and photovoltaic properties was investigated. A new monomer, $\mathrm{M} 2$, was prepared by capping (E)-3'-(2-(2,5-dibromothiophen-3-yl)vinyl)-

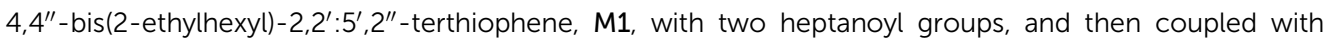
5, $5^{\prime}$-bis(trimethylstannyl)-2,2'-bithiophene via microwave-assisted Stille polymerization to produce a series of polythiophene derivatives with terthiophene-vinylene conjugated side chains, TTV-PTs. Copolymer P2 shows a down-shifted HOMO energy level, enhanced solubility, and red-shifted absorption, as compared with P1; however, the bulky side chains significantly disrupt the coplanarity of thiophene rings in the polymer backbone and the ability to self-assemble into an ordered structure. The GIXRD measurements reveal that the original crystallinity of P1 can be recovered by simply inserting a few 2,1,3-benzothiadiazole units into the polythiophene main chain in P2 through a random copolymerization route to yield a terpolymer, $\mathrm{P} 3$, which possesses excellent crystallinity, thereby causing $a$ three-fold increment in hole mobility. Furthermore, the $\mathrm{P} 1 / \mathrm{PC}_{61} \mathrm{BM}, \mathrm{P} 2 / \mathrm{PC}_{61} \mathrm{BM}$, and $\mathrm{P} 3 / \mathrm{PC}_{61} \mathrm{BM}$ solar devices exhibit power conversion efficiencies of $3.89 \%, 1.52 \%$, and $4.17 \%$, respectively, under AM1.5G illumination with an intensity of $100 \mathrm{~mW} \mathrm{~cm}^{-2}$.
\end{abstract}

\section{Introduction}

Molecular engineering of specific semiconducting conjugated polymers for use in high-performance organic electronic devices, such as field effect transistors (FETs), photo-detectors, light-emitting diodes (LEDs), and photovoltaics (PVs), requires a better understanding of the relationship between their chemical structure and optoelectronic properties. ${ }^{1-7}$ Several successful strategies for the structural design of conjugated polymers, such as donor-acceptor (D-A) copolymerization, ${ }^{8-10}$

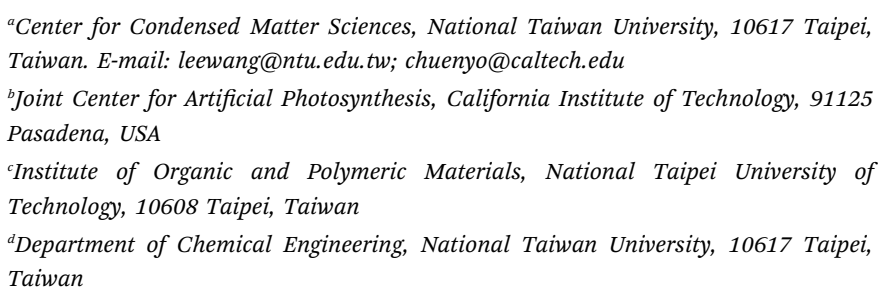

$\dagger$ Electronic supplementary information (ESI) available. See DOI: $10.1039 / \mathrm{c} 6 \mathrm{ra} 11738 \mathrm{~d}$ two-dimensional (2-D) conjugation, ${ }^{11-13}$ and side-chain engineering, ${ }^{14-16}$ have been developed to enhance their lightharvesting ability, charge mobility, self-assembling, solubility, and turning their molecular energy levels to meet the requirements of organic electronic devices., ${ }^{5,17-20}$ Poly(thienylenevinylene)s (PTVs), which is one of polythiophene derivatives (PTs) containing alternating thiophene and vinylene units along the main-chains, have been intensively studied for their photoelectrical property and photovoltaic applications, due to their good charge transport property.,21-25 In addition, previous literatures also have shown that polythiophene derivatives (PTs) with thienylene-vinylene conjugated side chains possess broader absorption spectra and relatively low-lying HOMO energy levels compared with their linear analogues, since the thienylene-vinylene conjugated side chains could extend the $\pi$-electron delocalization of polymer backbone.,26-30 For example, chemically grafting conjugated side chains onto polymer backbone through vinylene-linkage, such as thienylene-vinylene ${ }^{31}$ and bi(thienylenevinylene), ${ }^{11}$ is effective to extend the absorption range and down-shift the HOMO energy 
level of polythiophene. However, the steric hindrance of bulky branches frequently lowers the coplanarity of thiophene rings on the main chain, leading to weak crystallinity and low $\pi-\pi^{*}$ absorption intensity. ${ }^{28}$ To overcome this problem, unsubstituted thienyl moieties have been inserted into the backbone as spacer to reduce the grafting density and increase the distance between conjugated branches. ${ }^{32}$ Nevertheless, the introduction of such electron-rich spacer is accompanied by the substantial decline of solubility and the raise of HOMO level, thus complicating the fabrication process and limiting the maximum attainable open-circuit voltage $\left(V_{\mathrm{oc}}\right)$ of solar devices, respectively.

Recently, we established a new class of polythiophene derivatives with terthiophene-vinylene (TTV) conjugated side chains, P1, whose structure is illustrated in Fig. 1, by chemically attaching polythiophene backbone with branched side chains through vinylene bridge. ${ }^{13}$ This polymer has adequate solubility, an extended absorption spectrum, a deep HOMO level and, more importantly, retains excellent crystallinity. It has been well documented that the bandgap reduction of polymer donor in organic photovoltaics is crucial in enhancing the photocurrent and then the power conversion efficiency (PCE). One important approach toward red-shifting the absorption band is the integration of electron-rich and electron-deficient units into the polymer backbone or conjugated side chains that would enhance effectively intramolecular charge transfer (ICT) to reduce the optical bandgap. In comparison to alternative copolymerization of these monomers, the strategy of random copolymerization has advantages of further broadening the absorption region caused by multiple chromophores. ${ }^{18,28,30,33}$ Overall, these strategies, such as incorporating electron-withdrawing groups into polymer backbone and/or conjugated side chains, would be conducive to absorption ability of conjugated polymer.

Herein, we designed and synthesized two 2-D conjugated polymers, P2 and P3 (Fig. 1), by attaching two carbonyl groups to the TTV conjugated side chains and incorporating 2,1,3benzothiadiazole (BTD) units into the polymer backbone. Because of the attachment of two carbonyl groups to the TTV conjugated side chains, P2 displays a deeper HOMO energy level and better solubility, and its absorption band from conjugated side chain is red-shifted in comparison to P1. In addition, BTD, a planar and strongly electron-withdrawing unit, is widely used to build high-performance donor-acceptor copolymers. ${ }^{34,35}$
Importantly, due to the randomized incorporation of steric-less BTD units into the polymer backbone of terpolymer, P3, its presence not only broadened the polymers absorption band but also promoted its self-assembling ability. ${ }^{36}$ The best PSC devices based on $\mathrm{P3} / \mathrm{PC}_{61} \mathrm{BM}$ gave a $\mathrm{PCE}$ of $4.17 \%$ under $\mathrm{AM} 1.5 \mathrm{G}$ illumination with an intensity of $100 \mathrm{~mW} \mathrm{~cm}^{-2}$. The effects of molecular structure design on the optical, electrical, crystallographic, and photovoltaic properties of these copolymers were systematically investigated.

\section{Results and discussion}

The synthetic routes used to prepare the new monomer, M2, and the target copolymers are shown in Scheme 1. On the basis of the reactivity of $\mathbf{M 1}$, it was anticipated that Friedel-Crafts acylation would preferentially occur at the 5 and $5^{\prime \prime}$ positions of the terthiophene side chain. Therefore, the new monomer M2 was synthesized using M1, heptanoyl chloride, and aluminum chloride. A coupling constant of $c a \cdot 16.0 \mathrm{~Hz}$ in the ${ }^{1} \mathrm{H}$ NMR spectrum of M2 (Fig. S1 in the ESI $\dagger$ ) clearly indicates that the

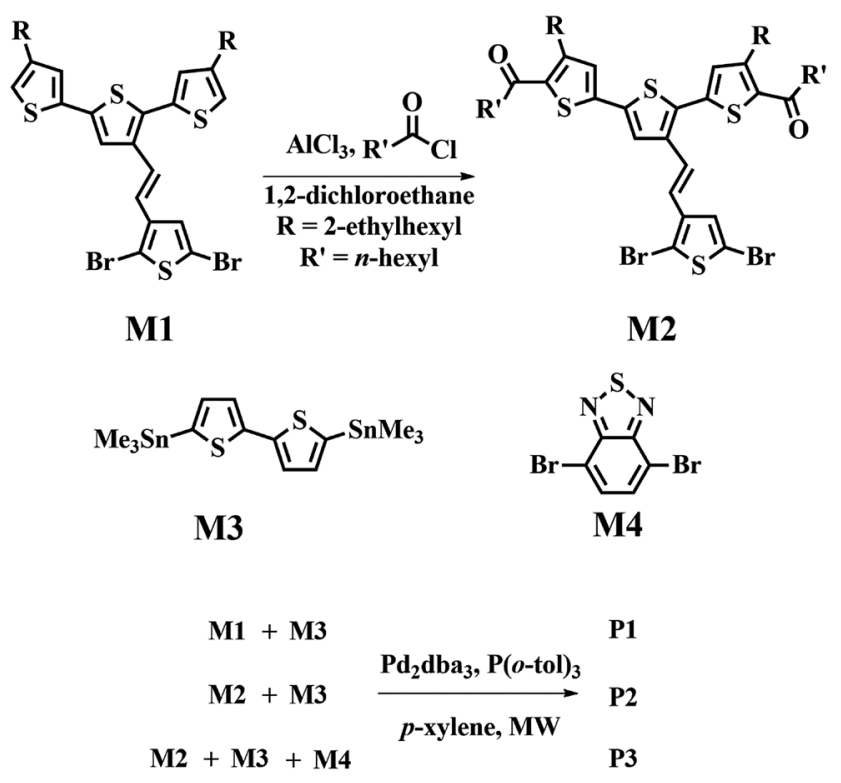

Scheme 1 Synthetic routes for monomers and the corresponding polymers.

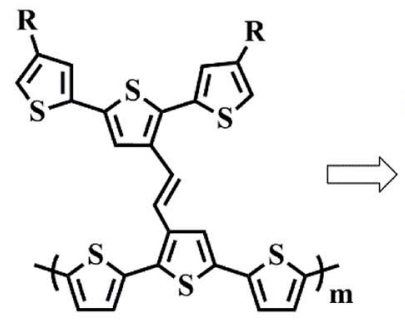

P1

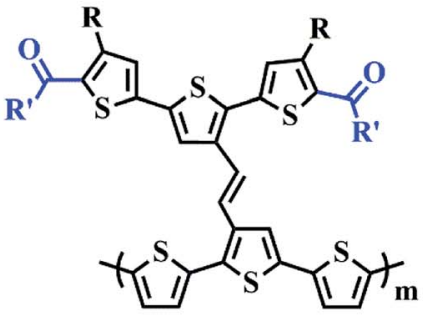

P2

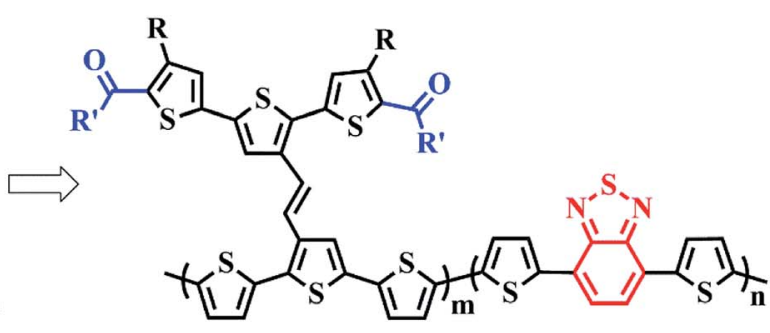

P3

Fig. 1 Chemical structures of P1, P2, and P3 (R=2-ethylhexyl; $\mathrm{R}^{\prime}=n$-hexyl). 
$E$-isomer is the exclusive product. Detailed characterization data for this monomer is given in the ESI. $\dagger$

All polymers were polymerized under microwave-assisted conditions. Microwave-assisted Stille polymerization lends itself very well to our polymerization, because conditions can be quickly optimized and the reaction time was dramatically shortened. ${ }^{37}$ We tried to simply optimize the polymerization conditions of P1 by varying the catalyst, monomer concentration, and microwave heating conditions. The results of the polymerization experiments are listed in Table S1 (ESI $\dagger$ ). The results show that lower catalyst content, higher monomer concentration, and longer reaction time seem to produce polymers with higher molecular weights and lower polydispersity index (PDI) in polymerization of P1.

The optimized polymerization conditions of $\mathbf{P 1}$ were further applied in the synthesis of $\mathbf{P 2}$ and P3. Terpolymer P3 was polymerized with a molar feed ratio of M2 : M3 : M4 of $2: 3: 1$. It is noteworthy that the polymerization of random copolymer P3 is highly reproducible by microwave-assisted polymerization. The raw products were precipitated into methanol and collected through a Soxhlet thimble by filtration, which was then subjected to repeated Soxhlet extraction with methanol, acetone, hexane, and methylene chloride to remove the small molecules and oligomers, and finally with chloroform to collect the target compounds.

$\mathbf{P 1}$ and $\mathbf{P 2}$ have comparable yields of $c a$. $80 \%$ and exhibit good solubility in common solvents such as tetrahydrofuran (THF), chloroform, chlorobenzene (CB), and $o$-dichlorobenzene
(oDCB). Moreover, gel permeation chromatography (GPC) shows that they have very similar molecular weight characteristics with number-average molecular weights of around $27 \mathrm{kDa}$ with respect to polystyrene standards, as indicated in Table 1. However, P3 displays lower solubility in THF than the other polymers and therefore it is unavailable to obtain the molecular weight data by GPC. By using elemental analysis, the average $\mathrm{m} /$ $n$ ratio in $\mathbf{P 3}$ was calculated to be 4.4 , indicating that there is $c a$. $18 \%$ BTD units into the polymer backbone in reality.

Thermal properties of all polymers were investigated by thermogravimetric analysis (TGA) and differential scanning calorimetry (DSC) analysis, as shown Fig. S7 in the ESI. $\dagger$ TGA plots reveal that the temperatures with $5 \%$ weight loss of P1, P2, and $\mathbf{P 3}$ are 449,419 , and $430{ }^{\circ} \mathrm{C}$, respectively, under $\mathrm{N}_{2}$ atmosphere at a heating rate of $10^{\circ} \mathrm{C} \mathrm{min}^{-1}$. All compounds exhibit excellent thermal stability with degradation temperatures $\left(T_{\mathrm{d}}\right)$ at $5 \%$ weight loss well beyond $400{ }^{\circ} \mathrm{C}$. DSC plots were measured up to $300^{\circ} \mathrm{C}$, P1 exhibits an obvious phase transition at $282.1^{\circ} \mathrm{C}$ which is considered its melting point. However, the other bulk samples display no apparent thermal transition.

UV-vis absorption spectra of the polymers in dilute CB solution and as spin-coated film on glass substrates are shown in Fig. 2. The corresponding absorption data of the polymers is summarized in Table 1. Comparison of the UV-vis spectra of P2 and P3 with control polymer $\mathbf{P 1}$ reveals how the structural modifications of the side and main chains affect the optical properties of branched-type 2-D PTs. First, in dilute CB solution, P2 displays two distinct absorption bands between 300 and $650 \mathrm{~nm}$. The low-energy band

Table 1 Molecular weight, thermal, optical, and electrochemical properties of the polymers

\begin{tabular}{llllllllll}
\hline Polymer & $M_{\mathrm{n}}{ }^{a}(\mathrm{kDa})$ & $\mathrm{PDI}^{a}$ & $T_{\mathrm{d}}{ }^{b}\left({ }^{\circ} \mathrm{C}\right)$ & Solution, $\lambda_{\max }{ }^{c}(\mathrm{~nm})$ & Film, $\lambda_{\max }{ }^{d}(\mathrm{~nm})$ & Film, $\lambda_{\text {onset }}{ }^{d}(\mathrm{~nm})$ & $E_{\mathrm{g}}^{\text {opte }}(\mathrm{eV})$ & $E_{\mathrm{HOMO}}(\mathrm{eV})$ & $E_{\mathrm{LUMO}}{ }^{g}(\mathrm{eV})$ \\
\hline P1 & 27.0 & 3.94 & 449 & 341,528 & $355 / 564$ & 654 & 1.90 & -4.90 \\
P2 & 27.7 & 2.81 & 419 & 398,510 & $406 / 557$ & 669 & -3.00 & -5.14 \\
P3 & $x$ & $X$ & 430 & 410,579 & $407 / 579$ & 743 & 1.65 & -5.07
\end{tabular}

${ }^{a} M_{\mathrm{n}}$ and PDI of the polymers were estimated by GPC using polystyrene as standards in THF. ${ }^{b} 5 \%$ weight-loss temperature measured by TGA under $\mathrm{N}_{2}$ atmosphere. ${ }^{c}$ Measured in dilute $\mathrm{CB}$ solution $\left(10^{-3} \mathrm{~g} \mathrm{~L}^{-1}\right) .{ }^{d}$ Measured on glass substrates spin-coated with polymers from a CB solution $(10 \mathrm{~g}$ $\left.\mathrm{L}^{-1}\right)$ followed by thermal annealing $\left(120{ }^{\circ} \mathrm{C}, 15 \mathrm{~min}\right) .{ }^{e}$ Estimated from the onset wavelength of the absorption spectra: $E_{\mathrm{g}}{ }^{\mathrm{opt}}=1240 / \lambda_{\text {onset. }}{ }^{f} \mathrm{HOMO}^{\mathrm{HO}}$ energy levels were evaluated by ultraviolet photoelectron spectroscopy (AC2 equipment) of thin polymer films on glass substrates. ${ }^{g}$ Calculated according to the equation: $E_{\mathrm{LUMO}}=E_{\mathrm{HOMO}}+E_{\mathrm{g}}^{\mathrm{opt}}(\mathrm{eV})$.
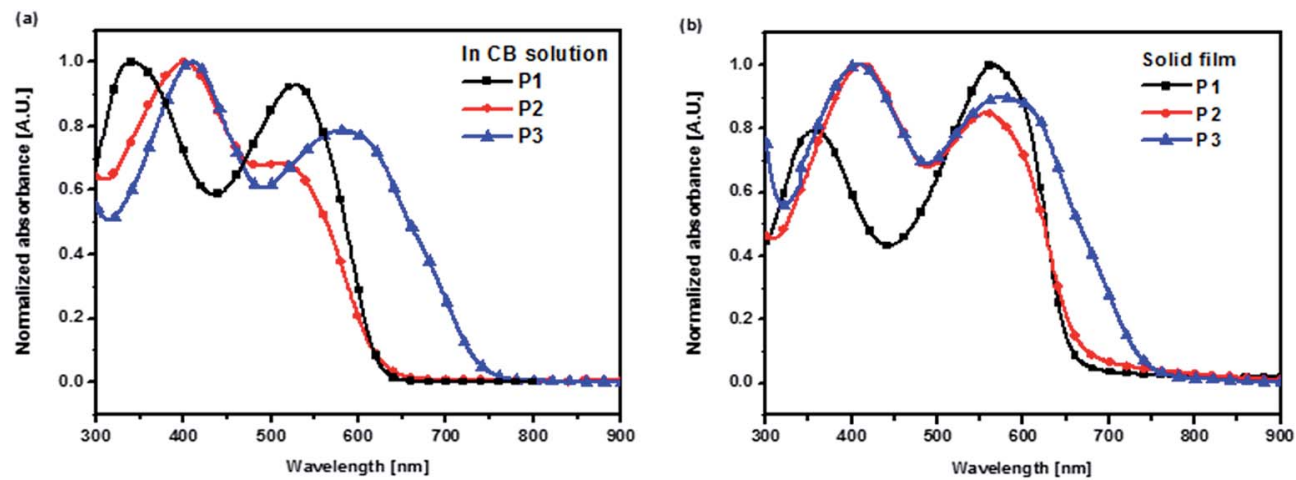

Fig. 2 UV-vis absorption spectra of polymers (a) in dilute CB solution at room temperature; (b) solid films prepared by spin-coating followed by thermal annealing at $120^{\circ} \mathrm{C}$ for $15 \mathrm{~min}$. 
that peaks at $\sim 535 \mathrm{~nm}$ corresponds to the $\pi-\pi^{*}$ transition of the conjugated backbone, whereas the high-energy (short wavelength) band that peaks at $\sim 398 \mathrm{~nm}$ and exhibits a distinct red-shift (of $57 \mathrm{~nm}$ ) compared to $\mathbf{P 1}$ that originates from the intramolecular charge transfer between two electron-withdrawing heptanoyl groups and the terthiophene unit in the TTV conjugated side chain. However, owing to the replacement of $\mathrm{H}$-atoms by two heptanoyl groups in the TTV conjugated side chain, the conjugated side chains become more bulky to disturb the coplanarity of the polymer backbone and therefore its $\pi-\pi^{*}$ transition peak is observed with a slight blue-shift (of $18 \mathrm{~nm}$ ) and relatively weak intensity compared to P1. Furthermore, in comparison with P2, random copolymer $\mathbf{P 3}$ possesses a significantly broader absorption region covering a wavelength range of 300-750 nm. P3 also exhibits two distinct absorption bands at $407 \mathrm{~nm}$ and $579 \mathrm{~nm}$. Because of the introduction of BTD units in the polymer backbone, the low-energy absorption band displays obvious red-shift that is mainly attributed to the ICT interaction of the BTD and BT units in the polymer backbone. Importantly, the partial bulky M2 units were replaced by less steric BTD units that would also enhance $\pi-\pi^{*}$ transition absorption due to reducing the twisting of polymer backbone. Through simple structural modifications of the side and main chains, we have successfully extended the absorption region of branched-type 2-D PTs, thereby enhancing their light-harvesting ability.

As shown in Fig. 2(b), the polymer films generally display redshifted and broader absorption than their corresponding solutions due to interchain associations and better planarity in the solid state. ${ }^{38}$ Therefore, the maximum values of the low-energy absorption peaks are red-shifted by ca. $36 \mathrm{~nm}, 47 \mathrm{~nm}$, and $23 \mathrm{~nm}$ for the P1, P2, and $\mathbf{P} 3$ films, respectively, in comparison with solutions. Moreover, the optical bandgaps $\left(E_{\mathrm{g}}^{\mathrm{opt}}\right)$ of P1, P2, and P3, estimated from the absorption onsets of their solid films, are $1.90,1.85$, and $1.67 \mathrm{eV}$, respectively. P3 obviously displays a lower bandgap than $\mathbf{P 2}$ because of the incorporation of strong electron-withdrawing BTD units into the polymer backbone. The absorption edge of random terpolymer P3 is red-shifted to the near-infrared region, implying that it has great potential for effective photon-harvesting and could achieve a high short-circuit current in PSCs. ${ }^{27}$

Molecular structural design is important for organic materials that directly has effect on polymer orientation in thin films, leading to decide the performance of charge transport. However, it's rare to be studied in 2-D PTs' system. Herein, to further understand the influence of molecular structure designs on solid-state crystallinity and polymer self-assembly in TTV-PTs, the two-dimensional grazing incidence X-ray diffraction (2D-GIXRD) technique was used to measure the intermolecular $d$-spacing and average crystallite size in the drop-cast thin films of polymer with thermal annealing procedure for investigating the behaviors of molecular packing orientation of P1-P3, as shown in Fig. S4. $\dagger$ The intermolecular $d$-spacing parameter and average crystallite size were determined from the diffraction peaks using Bragg's law and Scherrer's equations. ${ }^{39}$

As extracted from the out-of-plane 2D-GIXRD profile shown in Fig. 3, P1 thin film possesses a visible (100) diffraction peak at $2 \theta=3.01^{\circ}$ (corresponding to an interlayer $d$-spacing of

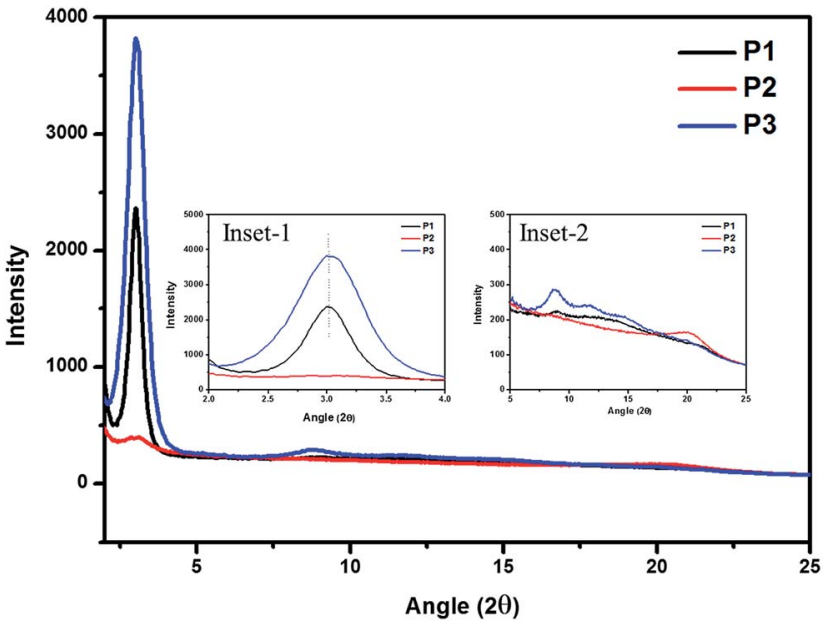

Fig. 3 Grazing incidence X-ray diffraction patterns of polymer films prepared by drop-cast followed by thermal annealing at $120{ }^{\circ} \mathrm{C}$ for $15 \mathrm{~min}$. The inset- 1 and inset- 2 shows the region around $2 \theta=2-4^{\circ}$ and $5-25^{\circ}$, respectively, in greater detail.

$2.54 \mathrm{~nm}$ with an average crystallite size of $16.5 \mathrm{~nm}$ ), indicating lamellar packing parallel to the surface normal with an edge-on (100) orientation of the conjugated plane. ${ }^{40}$ As two hydrogen atoms were replaced by two heptanoyl substituents at 5 and $5^{\prime \prime}$ positions of the terthiophene side chain of P1, polymer P2 thinfilm displayed amorphous nature that indicating the more bulky side groups in $\mathbf{P 2}$ hinder the molecular stacking. Therefore, although the additional two heptanoyl groups in TTV side chains could enhance the solubility and red-shift absorption in UV-vis region, it is destructive for polymer self-assembly and backbone coplanarity by larger side chains.

Interestingly, P3 displays a strong (100) diffraction peak at $2 \theta=3.01^{\circ}$ (corresponding to a lamellar $d$-spacing of $2.54 \mathrm{~nm}$ with an average crystallite size of $11.3 \mathrm{~nm}$ ). In other words, partial bulky $\mathbf{M} 2$ units were replaced by less sterically hindering BTD (M4) units in the polymer backbone that release enough free space to reduce the steric effect on the polymer backbone and promote molecular organization. This is an important strategy to induce polymer self-assembly for 2-D polythiophene derivatives by random copolymerization with less-steric units, such as 2,1,3benzothiadiazole. In addition, compared to P1, the FWHM and intensity of (100) diffraction peak for P3 thin films is broader and stronger, respectively, indicating $\mathbf{P} 3$ thin films have higher degree of crystallinity and smaller average crystalline grain.

The charge mobility of conjugated polymers exerts a significant influence on the FF value of PSC devices, ${ }^{41}$ and many studies have revealed that the hole mobility of a crystalline conjugated polymer is usually higher than that of an amorphous conjugated polymer and therefore is more comparable with the electron mobility in the active layer, where the electron mobility is dominated by fullerene. ${ }^{42}$ The hole mobilities of polymers were measured in a hole-only device (ITO/PEDOT:PSS/ pristine polymer/Au) using the space-charge-limited current (SCLC) method. Fig. S6(a) $\dagger$ which is plotted as $\ln \left(J_{\text {dark }} L^{3} V^{-2}\right)$ versus $\left(V L^{-1}\right)^{0.5}$ in ESI $\dagger$ shows the dependence of the measured 
current density on the applied voltage. The mobilities were calculated according to the following formula: ${ }^{43}$

$$
J=\frac{9}{8} \varepsilon_{\mathrm{r}} \varepsilon_{0} \mu_{0} \frac{V^{2}}{L^{3}} \exp \left(0.89 \sqrt{\frac{V}{E_{0} L}}\right),
$$

where $J$ denotes the current density, $\varepsilon_{\mathrm{r}}$ is the dielectric constant of the organic molecule, $\varepsilon_{0}$ is the permittivity of free space, $L$ is the thickness of the active layer, $V$ is the applied voltage, and $E_{0}$ is the characteristic field. The mobility of the polymer films was deduced from the intercept value of $\ln \left(\frac{9}{8} \varepsilon_{\mathrm{r}} \varepsilon_{0} \mu_{0}\right)$. Therefore, the hole mobility of pristine $\mathbf{P 1}, \mathbf{P 2}$, and $\mathbf{P} 3$ were determined to be $3.9 \times 10^{-4} \mathrm{~cm}^{2} \mathrm{~V}^{-1} \mathrm{~s}^{-1}, 3.8 \times 10^{-5} \mathrm{~cm}^{2} \mathrm{~V}^{-1} \mathrm{~s}^{-1}$, and $1.0 \times 10^{-4}$ $\mathrm{cm}^{2} \mathrm{~V}^{-1} \mathrm{~s}^{-1}$, respectively. It should be noted that thin film of $\mathbf{P 1}$ exhibited a diffraction peak at $2 \theta=20.17^{\circ}$, shown in inset figure in Fig. 3, that would be classified as face-on orientation and correspond to a $\pi-\pi$ stacking distance of $3.81 \AA$. Therefore, it is reasonable to explain that the pristine $\mathbf{P 1}$ thin film possesses the highest hole mobility by SCLC method, because it's well known that face-on polymer orientations have been suggested to promote the charge mobility by SCLC method and PSCs; ${ }^{\mathbf{4 4 , 4 5}}$ meanwhile, the pristine $\mathbf{P 3}$ thin film takes an edge-on orientation nature on the substrate which might be caused by the bulky side groups hindering the development of $\pi-\pi$ stacking of polymer backbone. Nevertheless, it is evident that the formation

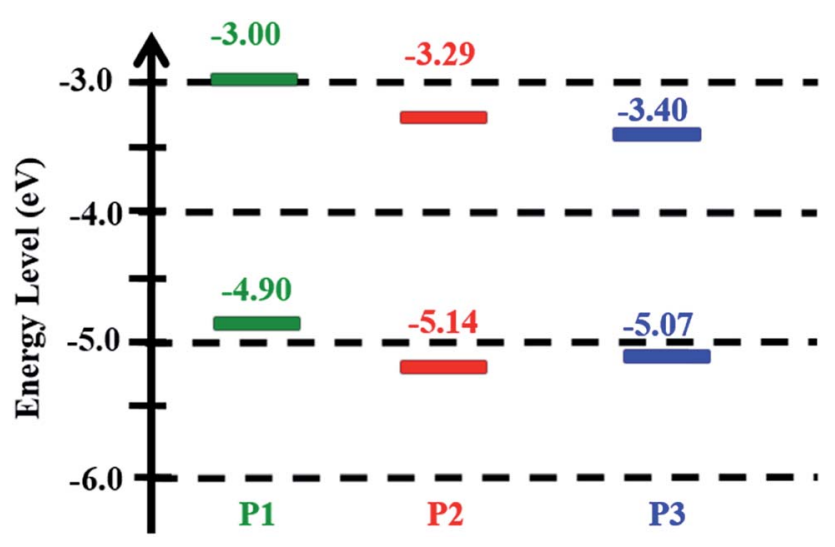

Fig. 4 Energy diagram of P1, P2, and P3. of an ordered polymer-chain structure improved the carrier mobility of the polymer material.

The highest occupied molecular orbital (HOMO) energies were estimated from the ionization potentials of spin-coated films determined by UV photoelectron spectroscopy in air using an AC2 photoelectron spectrometer (Riken Keiki Co.). ${ }^{46}$ Fig. S3† plots the square root of the counting rate (CR) as a function of the photon energy. The photoemission threshold energy, also called the work function, was determined from the crossing point of the background and yield lines. Therefore, the work functions of P1, P2, and P3, were found to be $-4.90 \mathrm{eV}$, $-5.14 \mathrm{eV}$, and $-5.07 \mathrm{eV}$, respectively (see Table 1 ) and the energylevel diagrams of polymers derived from AC2 photoelectron spectroscopy and UV-vis absorption data are shown in Fig. 4. Furthermore, the lowest unoccupied molecular orbital (LUMO) energies were calculated using the optical band gap $\left(E_{\mathrm{g}}^{\mathrm{opt}}\right)$ and the HOMO energies determined from AC2 measurement according to the following equation: $E_{\mathrm{LUMO}}=E_{\mathrm{HOMO}}+E_{\mathrm{g}}^{\mathrm{opt}}(\mathrm{eV})$.

By comparing with the HOMO of P1, the HOMO of $\mathbf{P 2}$ is $0.24 \mathrm{eV}$ deeper. Because two additional electron-withdrawing heptanoyl substituents attached to the 5 and $5^{\prime \prime}$ positions of the terthiophene side chain that enhance its air stability in ambient conditions, $\mathbf{P} 2$ possessed further down-shifted HOMO level than P1. Furthermore, M2 units were partially replaced by M4 units in the backbone of $\mathbf{P 3}$ such that the lower ratio of monomers containing conjugated side chains in the polymer backbone resulted in the HOMO rising. Similar results have also been observed for other 2-D PTs random copolymers. ${ }^{27,29,47}$ In addition, the differences $(>0.5 \mathrm{eV})$ in the LUMO levels of the polymers and $\mathrm{PC}_{61} \mathrm{BM}(\sim 4.20 \mathrm{eV})$ are still adequate enough for efficient charge transfer, even for the lowest LUMO in P3. ${ }^{27,48}$ The AC2 measurements reveal that our series of 2-D conjugated polymers have lower HOMO energies than rr-P3HT (ca. $-4.68 \mathrm{eV}$ under identical condition); this will be beneficial for the fabrication of photovoltaic devices with high $V_{\text {oc }}$ values.

The broader absorption bands and lower-lying HOMO energy levels of our polymers suggest that they might exhibit promising photovoltaic properties. Bulk heterojunction PSC devices were fabricated using P1, P2, or P3 as the electron donor, and $\mathrm{PC}_{61} \mathrm{BM}$ as the electron acceptor. The device structure is ITO/PEDOT:PSS/polymer: $\mathrm{PC}_{61} \mathrm{BM} / \mathrm{Ca} / \mathrm{Al}$. The cell performance was optimized by varying the polymer to $\mathrm{PC}_{61} \mathrm{BM}$
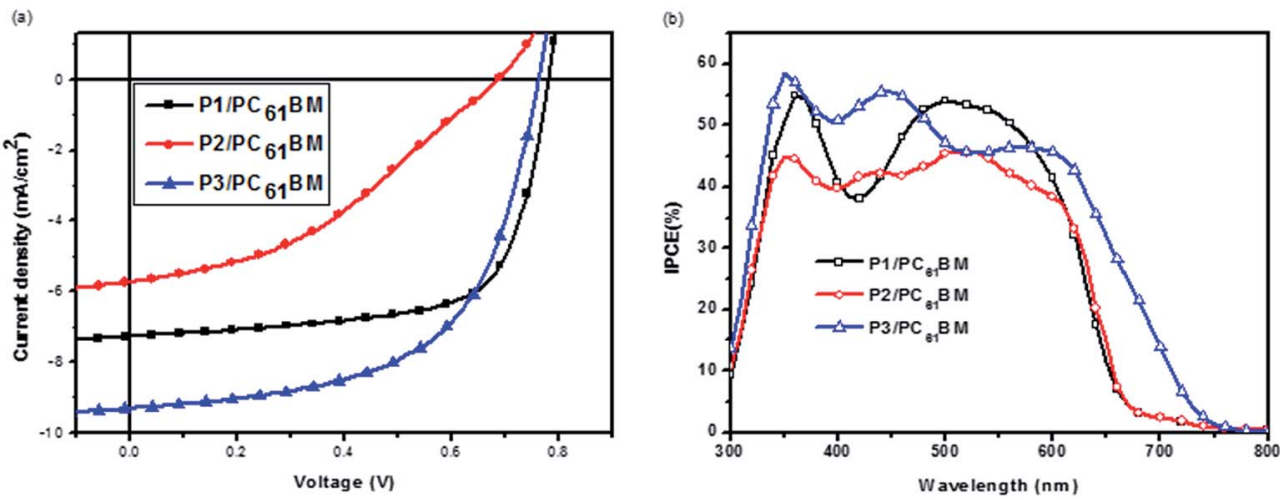

Fig. 5 (a) J-V curves (b) IPCE spectra of optimized polymer/PC ${ }_{61} B M$ devices under $A M 1.5 G$ illumination with an intensity of $100 \mathrm{~mW} \mathrm{~cm}^{-2}$. 
Table 2 Photovoltaic properties of polymer solar cell devices based on the polymers, P1, P2, and P3 with optimized ratios of PC 61 BM under AM1.5G illumination with an intensity of $100 \mathrm{~mW} \mathrm{~cm}^{-2}$

\begin{tabular}{|c|c|c|c|c|c|c|}
\hline Polymer/fullerene & $V_{\mathrm{oc}}(\mathrm{mV})$ & $J_{\mathrm{sc}}\left(\mathrm{mA} \mathrm{cm}{ }^{-2}\right)$ & $\mathrm{FF}(\%)$ & PCE (\%) & $R_{\mathrm{sh}}\left(\mathrm{k} \Omega \mathrm{cm}^{2}\right)$ & $R_{\mathrm{S}}\left(\Omega \mathrm{cm}^{2}\right)$ \\
\hline $\mathbf{P 1} / \mathrm{PC}_{61} \mathrm{BM}^{a}$ & $788 \pm 4$ & $7.24 \pm 0.05$ & $67.76 \pm 0.27$ & $3.87 \pm 0.02(3.89)$ & $1.01 \pm 0.03$ & $9.03 \pm 0.27$ \\
\hline $\mathbf{P} 2 / \mathrm{PC}_{61} \mathrm{BM}^{b}$ & $688 \pm 4$ & $5.50 \pm 0.28$ & $38.25 \pm 0.44$ & $1.44 \pm 0.08(1.52)$ & $0.47 \pm 0.03$ & $58.94 \pm 2.75$ \\
\hline
\end{tabular}

${ }^{a}$ Blend ratio $10: 8(\mathrm{w} / \mathrm{w})$, in CB solvent, annealing at $100{ }^{\circ} \mathrm{C}$ for $10 \mathrm{~min} .{ }^{b}$ Blend ratio $10: 8(\mathrm{w} / \mathrm{w})$, in $o$-DCB solvent, annealing at $80{ }^{\circ} \mathrm{C}$ for $10 \mathrm{~min}$. ${ }^{c}$ Blend ratio $7: 7(\mathrm{w} / \mathrm{w})$, in $o$-DCB solvent, annealing at $120^{\circ} \mathrm{C}$ for $10 \mathrm{~min}$.

blend ratio in the active layer and thermal annealing temperature. The $J-V$ curves of the optimized polymer/fullerene devices under AM1.5G illumination with an intensity of $100 \mathrm{~mW} \mathrm{~cm} \mathrm{~cm}^{-2}$ are plotted in Fig. 5(a) and the relevant photovoltaic characteristics are listed in Table 2. The highest PCEs (\%) for each PSC device are $3.89 \%\left(\mathbf{P 1} / \mathrm{PC}_{61} \mathrm{BM} 1: 0.8 \mathrm{w} / \mathrm{w}\right), 1.52 \%\left(\mathbf{P} 2 / \mathrm{PC}_{61} \mathrm{BM}\right.$ $1: 0.8 \mathrm{w} / \mathrm{w})$, and $4.17 \%\left(\mathbf{P 3} / \mathrm{PC}_{61} \mathrm{BM} 1: 1 \mathrm{w} / \mathrm{w}\right)$.

The incident photo-to-electron conversion efficiencies (IPCE) of the optimized polymer/fullerene devices under AM1.5G illumination with an intensity of $100 \mathrm{~mW} \mathrm{~cm} \mathrm{~cm}^{-2}$ are plotted in Fig. 5(b). The $J_{\mathrm{sc}}$ values calculated by integrating the IPCE data with the AM1.5G spectrum were 7.64, 5.86 and $9.55 \mathrm{~mA} \mathrm{~cm}^{-2}$ for P1, P2 and P3 devices, respectively. The IPCE results not only agree with the measured $J_{\mathrm{sc}}$ values, considering that an error of 3-6\% commonly takes place for the IPCE measurements, but also exhibit well-matched curves with their optical absorptions. ${ }^{27,30,49}$ The IPCE spectra of the P1/PC ${ }_{61} \mathrm{BM}(1: 0.8 \mathrm{w} / \mathrm{w})$ device covers a wavelength range of 350-650 $\mathrm{nm}$. Moreover, the device based on $\mathbf{P 2} / \mathbf{P C}_{61} \mathrm{BM}$ and $\mathbf{P} 3 / \mathrm{PC}_{61} \mathrm{BM}$ show higher IPCE values in the wavelength range of $400-430 \mathrm{~nm}$ and $370-$ $475 \mathrm{~nm}$, respectively, than $\mathbf{P 1} / \mathrm{PC}_{61} \mathrm{BM}$. This result reveals that two additional heptanoyl substituents attached to the TTV conjugated side chain can effectively enhance absorption bands between 350 and $480 \mathrm{~nm}$ as shown in Fig. 2(b) and further lead to increase photocurrent generation in the region. However, the $\mathbf{P} 2 / \mathrm{PC}_{61} \mathrm{BM}$ device shows a rather low IPCE over most of the (a) $\mathbf{P 1} / \mathbf{P C}_{61} \mathbf{B M}$
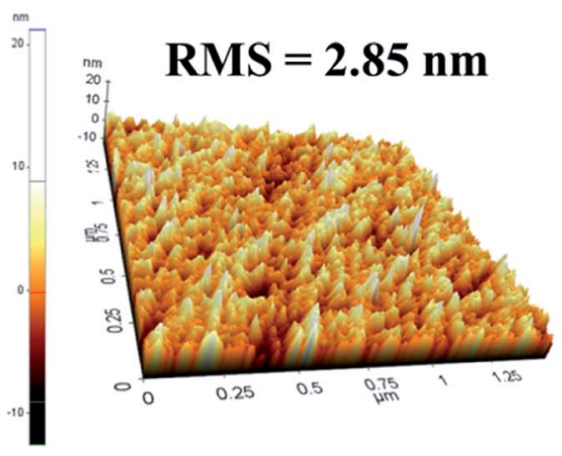

(d) $\mathbf{P 1} / \mathrm{PC}_{61} \mathbf{B M}$

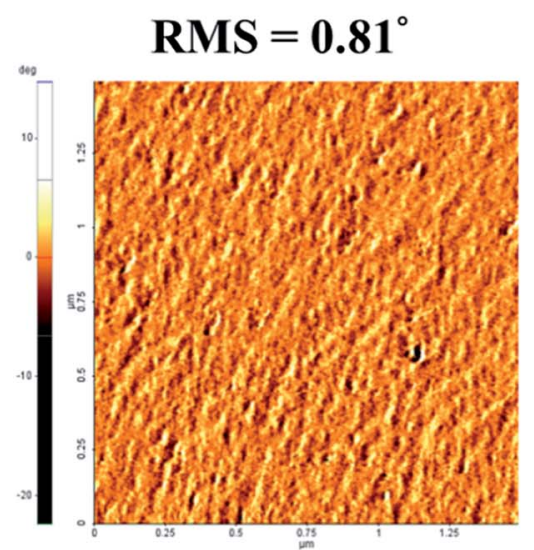

(b) $\mathrm{P} 2 / \mathrm{PC}_{61} \mathrm{BM}$

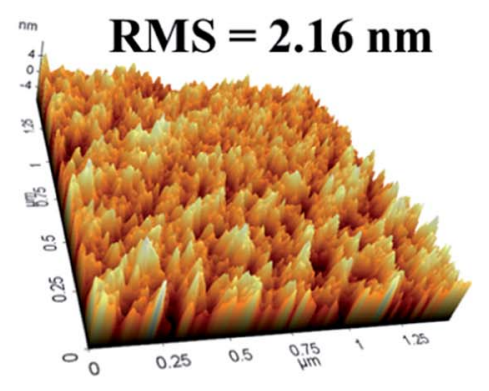

(c) $\mathbf{P} 3 / \mathbf{P C}_{61} \mathbf{B M}$

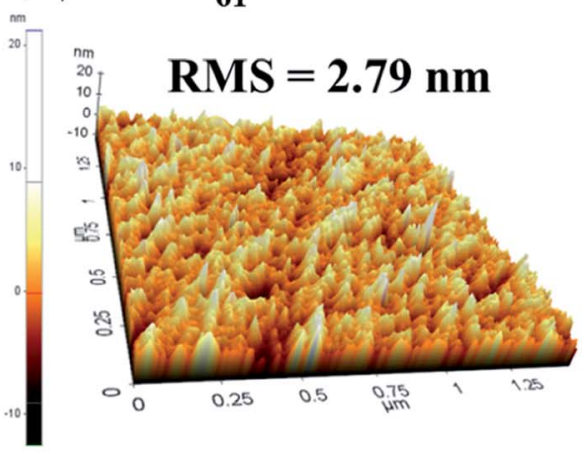

(e) $\mathbf{P 2} / \mathrm{PC}_{61} \mathrm{BM}$

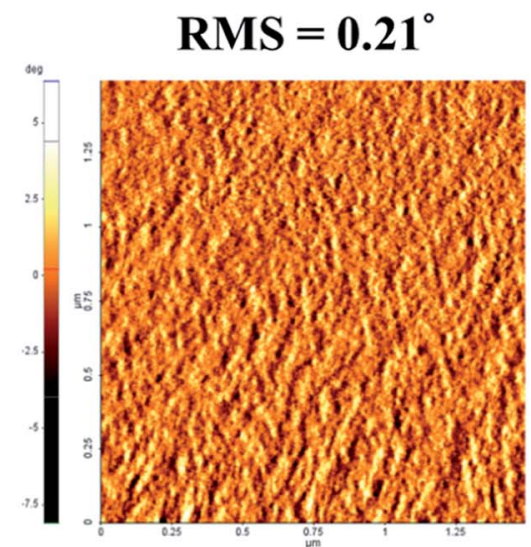

(f) $\mathbf{P 3} / \mathbf{P C}_{61} \mathbf{B M}$

$$
\mathbf{R M S}=\mathbf{0 . 9 3}^{\circ}
$$

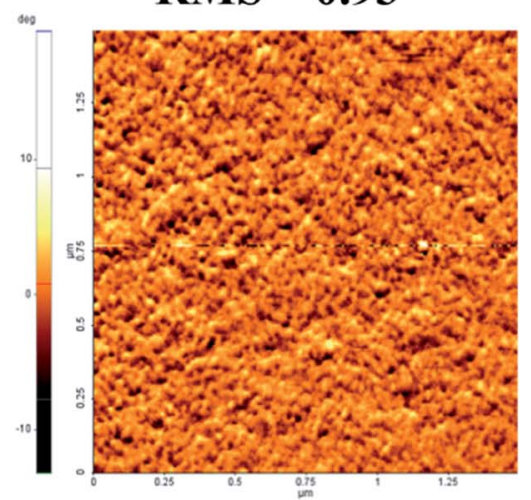

Fig. 6 AFM $(a-c)$ topography images and $(d-f)$ phase images of spin-coated films of polymer/PC ${ }_{61} B M$ blends. The scan sizes for all images are 2 $\mu \mathrm{m} \times 2 \mu \mathrm{m}$. 
response range, thus causing its lower $J_{\mathrm{sc}}$ and PCE. For the $\mathbf{P 3} / \mathrm{PC}_{61} \mathrm{BM}$ device, the active region of the IPCE curve covers the broadest wavelength range from 300 to $750 \mathrm{~nm}$. The existence of the two heptanoyl substituents in P3 promote the higher IPCE values from 370 to $475 \mathrm{~nm}$ compared to the P1 device; meanwhile, by incorporating BTD units into the $\mathbf{P 3}$ backbone, the IPCE curve is further extended to $750 \mathrm{~nm}$, thus causing this device to have the broadest IPCE region and highest $J_{\text {sc }}$.

The electron and hole mobilities of the blended films were determined by using the SCLC method to gain an insight into their effective charge carrier mobilities in the optimized blend weight ratio. Experimental results shown in Fig. S6(b) and (c) and Table S2 $\uparrow$ indicate that the trend in hole mobility of the blended films is the same as that for the series resistance $\left(R_{\mathrm{S}}\right)$. As a result, the hole mobility of $\mathbf{P 2} / \mathrm{PC}_{61} \mathrm{BM}$ is approximately two orders of magnitude lower than the electron mobility, which leads to unbalanced charge carrier transport and recombination, and may be responsible for the poor photovoltaic characteristics observed.

The open-circuit voltage $\left(V_{\mathrm{oc}}\right)$ of PSC device is mainly related to the difference between the HOMO of the donor and LUMO of the acceptor. ${ }^{48}$ Thus, because of the low-lying HOMO energy levels of PTs containing conjugated side chains, an average $V_{\text {oc }}$ of $788 \mathrm{mV}$ was obtained from the $\mathbf{P 1} / \mathrm{PC}_{61} \mathrm{BM}$ devices, which substantially exceeds the commonly reported $V_{\text {oc }}(\sim 0.6 \mathrm{~V})$ for devices based on $\mathrm{P} 3 \mathrm{HT} / \mathrm{PC}_{61} \mathrm{BM}^{50-52}$ However, the lowest $V_{\mathrm{oc}}$ value was observed for the $\mathbf{P} 2 / \mathrm{PC}_{61} \mathrm{BM}$ device which is quite poorly consistent with the position of the P2 HOMO energy level. The non-linear trend is decided by a couple of other factors besides the HOMO levels of the polymers, such as the dark current, blend morphology of the photoactive layers, and interface resistance. ${ }^{\mathbf{3 0 , 3 4 , 5 3 - 5 5}}$ Fig. S5 (shown in ESI†) shows dark $J-V$ curves of polymer $/ \mathrm{PC}_{61} \mathrm{BM}$ devices. The dark current of the $\mathbf{P} 2 / \mathrm{PC}_{61} \mathrm{BM}$ device was obviously larger than that of the $\mathbf{P 1} / \mathrm{PC}_{61} \mathrm{BM}$ device implying that serious recombination from dark carriers might have caused a loss of open-circuit voltage.

The morphology of photoactive layer plays a decisive role in determining the photovoltaic characteristics of PSC devices. ${ }^{\mathbf{5 6 - 5 8}}$ Herein, atomic force microscopy (AFM) was used to investigate the morphologies of the spin-coated films of polymers $/ \mathrm{PC}_{61} \mathrm{BM}$ on top of ITO/PEDOT:PSS, which were prepared by using the same procedure and parameters for preparing the photoactive layers. As shown in Fig. 6, the $\mathbf{P 2} / \mathrm{PC}_{61} \mathrm{BM}$ blend film exhibits the smoothest surface and the least degree of phase separation with a root-mean-square (RMS) roughness of $2.16 \mathrm{~nm}$ and a phase degree of $0.21^{\circ}$. However, $\mathbf{P 2} / \mathrm{PC}_{61} \mathrm{BM}$ has the slowest hole mobility of $1.1 \times 10^{-6} \mathrm{~cm}^{2} \mathrm{~V}^{-1} \mathrm{~s}^{-1}$, which is also only around one-third of that of pristine P2. These findings suggest that the polymer chains of $\mathbf{P 2}$ form homogeneous mixture with $\mathrm{PC}_{61} \mathrm{BM}$ and are unable to effectively segregate into continuous and unhindered pathways for conduction of holes to the anode. Therefore, the $J_{\text {sc }}$ of the $\mathbf{P 2} / \mathrm{PC}_{61} \mathrm{BM}$ solar cell is much smaller than that of both $\mathbf{P 1} / \mathrm{PC}_{61} \mathrm{BM}$ and $\mathbf{P 3} / \mathrm{PC}_{61} \mathrm{BM}$ devices.

\section{Conclusions}

We have successfully incorporated electron-withdrawing units, heptanoyl group and BTD moiety, into the TTV conjugated side chains and polythiophene backbone to synthesize TTV-PTs, P2 and P3. Compared with their parent analogue, these polymers possess apparently red-shifted absorption bands as well as down-shifted HOMO and LUMO levels that are beneficial to improve the polymer donor's light-harvesting ability and lift the $V_{\text {oc }}$ of solar cells. However, the steric hindrance of bulky heptanoyl groups in P2 significantly twists the polymer backbone, not only shortening the conjugation length but also lowering the crystallinity and then hole mobility. It is interesting to note that the crowding effect of oversized side groups can be completely relaxed by the insertion of $18 \%$ BTD units into the polymer main chain through a simple random copolymerization method and, therefore, the resulting terpolymer P3 has broad absorption band, excellent crystallinity and good carrier mobility. Consequently, the bulk heterojunction solar cell fabricated from $\mathrm{P} 3 / \mathrm{PC}_{61} \mathrm{BM}$ exhibits a promised PCE of $4.17 \%$ with a $V_{\mathrm{oc}}$ of $770 \mathrm{mV}$, a $J_{\mathrm{sc}}$ of $9.3 \mathrm{~mA} \mathrm{~cm}^{-2}$ and an $\mathrm{FF}$ of $58 \%$. A further improvement can be made by introducing larger solubilizing group onto the TTV unit to allow more BTD to be merged into the backbone. More importantly, this study offers an easy and useful strategy to design highly crystalline 2D conjugated polymers for developing high-performance polymer solar cells.

\section{Experimental section}

\section{Materials}

(E)-3'-(2-(2,5-Dibromothiophen-3-yl)vinyl)-4,4" -bis(2-ethylhexyl)$2,2^{\prime}: 5^{\prime}, 2^{\prime \prime}$-terthiophene (M1), ${ }^{59} \quad 5,5^{\prime}$-bis(trimethylstannyl)-2, $2^{\prime}$ bithiophene (M3), ${ }^{60}$ 4,7-dibromo-2,1,3-benzothiadiazole (M4) ${ }^{61}$ were prepared via literature procedures. Toluene (Acros Organics, 99+\%, extra pure) and $p$-xylene (Acros Organics, 99+\%, extra pure) and methylene chloride (ECHO Chemical, ACS Grade, 99.5\%) are dried over calcium hydride (Acros Organics, $c a$. $93 \%$, extra pure, $10-100 \mathrm{~mm}$ pieces) under $\mathrm{N}_{2}$ and stored with molecular sieves in a round-bottom flask under inert atmosphere. Flash chromatography was performed over silica gel (230-400 mesh).

\section{(E)-1,1'-(3'-(2-(2,5-Dibromothiophen-3-yl)vinyl)-4,4" -bis(2-} ethylhexyl)-[2,2':5' $2^{\prime \prime}$-terthiophene $]-5,5^{\prime \prime}$-diyl)bis(heptan-1one) (M2)

A solution of $\mathrm{AlCl}_{3}$ (Acros Organics, 99\%, $346.7 \mathrm{mg}, 2.6 \mathrm{mmol}$ ) in anhydrous 1,2-dichloroethane $(50 \mathrm{~mL})$ was added to a $100 \mathrm{~mL}$ Schlenk flask under $\mathrm{N}_{2}$ atmosphere. Heptanoyl chloride (Alfa Aesar, 99\%, $0.4 \mathrm{~mL}, 2.6 \mathrm{mmol}$ ) freshly distilled was then slowly added dropwise to the solution. The mixture was stirred at room temperature for $30 \mathrm{~min}$ and then cooled to $0{ }^{\circ} \mathrm{C}$. Subsequently, M1 (960 mg, $1.3 \mathrm{mmol}$ ) in anhydrous 1,2-dichloroethane $(10 \mathrm{~mL})$ was slowly added dropwise to the solution, causing the color of the suspension to change from light yellow to deep-red. The mixture was warmed to room temperature and stirred overnight. Then $2 \mathrm{M}$ hydrochloric acid $(100 \mathrm{~mL})$ was slowly added to quench the reaction and the resulting mixture were extracted twice with $40 \mathrm{~mL}$ dichloromethane, then the organic phase was combined, washed several times with saturated 
sodium acetate solution and water, and dried with $\mathrm{MgSO}_{4}$. After removal of the solvent, the residue was purified by flash column chromatography (eluent: hexane $/ \mathrm{CH}_{2} \mathrm{Cl}_{2}, 1: 1, \mathrm{v} / \mathrm{v}$ ), yielding a pale-yellow oil M2 (601.0 mg, $0.62 \mathrm{mmol}, 48 \%) .{ }^{1} \mathrm{H}$ NMR (400 $\left.\mathrm{MHz}^{\mathrm{CDCl}}{ }_{3}\right) \delta 7.43(\mathrm{~s}, 1 \mathrm{H}), 7.07(\mathrm{~d}, 1 \mathrm{H}, J=16 \mathrm{~Hz}), 7.07(\mathrm{~s}, 1 \mathrm{H})$, $7.03(\mathrm{~s}, 1 \mathrm{H}), 6.98(\mathrm{~s}, 1 \mathrm{H}), 6.87(\mathrm{~d}, 1 \mathrm{H}, J=16 \mathrm{~Hz}), 2.99-2.88(\mathrm{~m}$, $4 \mathrm{H}), 2.81-2.76(\mathrm{~m}, 4 \mathrm{H}), 1.76-1.65(\mathrm{~m}, 6 \mathrm{H}), 1.35-1.26(\mathrm{~m}, 28 \mathrm{H})$, 0.90-0.87 (m, 18H); ${ }^{13} \mathrm{C} \mathrm{NMR}\left(100 \mathrm{MHz}, \mathrm{CDCl}_{3}\right) \delta$ 193.26, 193.21, 150.65, 150.34, 138.72, 138.57, 137.24, 137.11, 136.19, 134.78, 132.43, 131.85, 129.08, 127.13, 123.54, 123.33, 122.76, 112.32, $110.87,42.40,42.30,40.19,34.50,32.66,32.55,31.60,28.95$, 28.68, 28.62, 25.74, 24.76, 24.70, 23.06, 22.49, 14.08, 14.01, 10.71 ppm; HRMS (ESI ${ }^{+}$): $m / z$ calcd for $\mathrm{C}_{48} \mathrm{H}_{67} \mathrm{O}_{2} \mathrm{Br}_{2} \mathrm{~S}_{4}: 963.2365\left[\mathrm{M}^{+}\right]$; found: 963.2365 .

\section{Microwave-assisted polymerization procedure}

Monomers were weighted into microwave tubes (G10) and then the tubes were subjected to three successive cycles of vacuum followed by refilling with nitrogen. After addition of Pd-catalyst (Alfa Aesar, tris(dibenzylideneacetone)dipalladium(0), $\left[\mathrm{Pd}_{2}(\mathrm{dba})_{3}\right], \mathrm{Pd} 21.5 \%$ min; Acros Organics, tri-o-tolylphosphine, 99\%; Acros Organics, tetrakis(triphenylphosphine)palladium(0), $\left.\left[\mathrm{Pd}\left(\mathrm{PPh}_{3}\right)_{4}\right], 99 \%\right)$ in toluene or $p$-xylene solution (3 mol\% relative to 5, $5^{\prime}$-bis(trimethylstannyl)-2,2'-bithiophene, M3), the tubes were subjected to the reaction conditions in a microwave reactor. The heating condition: raise temperature from r.t. to $200{ }^{\circ} \mathrm{C}$ as fast as possible; hold the temperature $60 \mathrm{~min}$; cool down to $55{ }^{\circ} \mathrm{C}$. Each raw product was dissolved in toluene, then precipitated into methanol and collected through a Soxhlet thimble by filtration and then subjected to consecutive Soxhlet extractions with methanol, acetone, hexane, and methylene chloride to remove the small molecules and oligomers, and finally with chloroform to collect the target compounds.

P1 is synthesized according to the procedure with M1 (182.5 $\mathrm{mg}, 0.247 \mathrm{mmol})$ and $\mathbf{M} 3(122.3 \mathrm{mg}, 0.249 \mathrm{mmol})$ in $5.0 \mathrm{~mL}$ p-xylene, yielding P1 (154.6 mg, 84.1\%).

P2 is synthesized according to the procedure with M2 (167.4 $\mathrm{mg}, 0.174 \mathrm{mmol})$ and $\mathbf{M} 3(86.1 \mathrm{~g}, 0.175 \mathrm{mmol})$ in $3.5 \mathrm{~mL}$ p-xylene, yielding P2 (136.5 mg, 81.0\%).

P3 is synthesized according to the procedure with $\mathbf{M} 2$ (203.6 $\mathrm{mg}, 0.211 \mathrm{mmol}), \mathbf{M} 3$ (156.0 $\mathrm{mg}, 0.317 \mathrm{mmol})$ and $\mathbf{M 4}(31.1 \mathrm{mg}$, $0.105 \mathrm{mmol}$ ) in $6.3 \mathrm{~mL} p$-xylene, yielding P3 (104.5 mg, 49.5\%). Elemental analysis: found (average value): $\mathrm{S}, 20.620 \% ; \mathrm{H}$, 7.221\%; C, 68.015\%; N, 0.610\%.

\section{Characterization and instrumentation}

Microwave assisted polymerizations were performed in Anton Paar Monowave 300 microwave reactor. ${ }^{1} \mathrm{H}$ NMR and ${ }^{13} \mathrm{C}$ NMR spectra were recorded at $400 \mathrm{MHz}$ on Bruker DRX-400 spectrometer. All NMR spectra were calibrated by chloroformd $\left(\mathrm{CDCl}_{3}\right)$ where ${ }^{1} \mathrm{H}$ NMR chemical shifts of $\mathrm{CDCl}_{3}$ is $7.23 \mathrm{ppm}$; in addition, ${ }^{13} \mathrm{C} \mathrm{NMR}$ of $\mathrm{CDCl}_{3}$ is $77.0 \mathrm{ppm}$. Microwave assisted polymerizations were performed in Anton Paar Monowave 300 microwave reactor. Thermal gravimetric analysis (TGA) was measured on TA Instruments Hi-Res TGA 2950 and differential scanning calorimetry (DSC) was recorded on
PerkinElmer DSC 8000 under $\mathrm{N}_{2}$ atmosphere at a heating rate of $10{ }^{\circ} \mathrm{C} \mathrm{min}^{-1}$. Ultraviolet-visible absorption (UV-vis) spectra were recorded on a JASCO MD-2010 spectrometer. Gel permeation chromatography (GPC) was conducted at $40{ }^{\circ} \mathrm{C}$ using two Jordi DVB mixed-bed columns $(250 \times 10 \mathrm{~mm}$; suitable for separating polymers with molecular weights from $3 \times 10^{3}$ to $5 \times 10^{6}$ $\mathrm{g} \mathrm{mol}^{-1}$ ) using THF as the eluent at a flow rate of $1.0 \mathrm{~mL} \mathrm{~min}{ }^{-1}$ on a JASCO instrument that was equipped with UV-vis and refractive index (RI) detectors connected in series. 2D-GIXRD measurements were carried out on the wiggler beamline BL17A1 of the National Synchrotron Radiation Research Center (NSRRC, Taiwan), with a wavelength of $1.333 \AA$ delivered from a superconducting wavelength-shifting magnet and a $\operatorname{Si}(111)$ triangular crystal monochromator (TCM). The grazing angle was large enough to probe the interior of the films and meantime small enough to increase the X-ray path length within the films by orders of magnitude. ${ }^{62}$ The data were recorded by a Mar3450 image plate with exposure duration 60 second. The two-dimensional diffraction pattern was converted to a one dimensional powder diffraction profile by fit-2D program. The diffraction patterns are fitted in the one dimensional powder diffraction spectra using Gauss function of OriginPro 8 to locate the peak positions and calculate the full-width at halfmaximum. The work functions of materials were measured using an AC2 photoelectron spectrometer (Riken Keiki Co.). Atomic force microscopy (AFM) images were captured using taping model in Digital Instruments Nanoscope III. The AFM samples were prepared by spin-coating the blend solution on a ITO/PEDOT:PSS substrate.

\section{Device fabrication}

The polymer solar cells (PSCs) were fabricated with a configuration of ITO/PEDOT:PSS/active layer/Ca/Al. The ITO glasses were cleaned by a sequential ultrasonic treatment in detergent, deionized water, acetone, and isopropanol for $20 \mathrm{~min}$. Then PEDOT:PSS was filtered through a $0.2 \mu \mathrm{m}$ filter and spin-coated at $3500 \mathrm{rpm}$ for $30 \mathrm{~s}$ on top of ITO electrode. Subsequently, the PEDOT:PSS film was baked at $140{ }^{\circ} \mathrm{C}$ for $10 \mathrm{~min}$ in the air, and then moved into a glovebox. The blend solution of $\mathrm{PC}_{61} \mathrm{BM}$ and synthesized polymers in a solvent was filtered with/without a $0.45 \mu \mathrm{m}$ filter and spin-coated at $800 \mathrm{rpm}$ for $30 \mathrm{~s}$ on top of the PEDOT:PSS layer. These devices were thermally annealed at various temperatures for $10 \mathrm{~min}$, followed by capping with $\mathrm{Ca}$ $(\sim 20 \mathrm{~nm})$ and then $\mathrm{Al}(\sim 60 \mathrm{~nm})$ in a thermal evaporator at a base pressure of $c a .10^{-6} \mathrm{~Pa}$. The active area of the devices is $0.06 \mathrm{~cm}^{2}$. The current density-voltage measurements of the devices were conducted on a computer-controlled Keithley 2400 Source Measure Unit under AM1.5G simulated solar irradiation at $100 \mathrm{~mW} \mathrm{~cm}^{-2}$. The light incident intensity was calibrated by a mono-Si reference cell with a KG5 filter (PV Measurements, Inc.), which was pre-calibrated by the National Renewable Energy Laboratory. The SCLC measurements were carried out using a Keithley 2400 source meter under dark condition. The IPCE spectra were recorded under illumination by a xenon lamp and a monochromator (TRIAX 180, JOBIN YVON), and the light 
intensity was calibrated by using an OPHIR 2A-SH thermopile detector.

\section{Acknowledgements}

This research was financially supported by National Taiwan University, Academia Sinica (AS-103-SS-A02), and the Ministry of Science and Technology of the Republic of China (MOST 1022113-M-002-003-MY3; MOST 105-3113-E-102-010). The authors thank the instrumentation center sponsored by Ministry of Science and Technology and National Taiwan University for NMR, elemental analysis and TEM experiments.

\section{References}

1 J. Mei and Z. Bao, Chem. Mater., 2014, 26, 604-615.

2 C. Lu, H. C. Wu, Y. C. Chiu, W. Y. Lee and W. C. Chen, Macromolecules, 2012, 45, 3047-3056.

3 P. M. Beaujuge and J. R. Reynolds, Chem. Rev., 2010, 110, 268-320.

4 A. C. Grimsdale, K. Leok Chan, R. E. Martin, P. G. Jokisz and A. B. Holmes, Chem. Rev., 2009, 109, 897-1091.

5 J. Mei, Y. Diao, A. L. Appleton, L. Fang and Z. Bao, J. Am. Chem. Soc., 2013, 135, 6724-6746.

6 K. Pu, A. J. Shuhendler, J. V. Jokerst, J. Mei, S. S. Gambhir, Z. Bao and J. Rao, Nat. Nanotechnol., 2014, 9, 233-239.

7 L. Feng, C. Zhu, H. Yuan, L. Liu, F. Lv and S. Wang, Chem. Soc. Rev., 2013, 42, 6620-6633.

8 Z.-G. Zhang and J. Wang, J. Mater. Chem., 2012, 22, 41784187.

9 P.-C. Jwo, Y.-Y. Lai, C.-E. Tsai, Y.-Y. Lai, W.-W. Liang, C.-S. Hsu and Y.-J. Cheng, Macromolecules, 2014, 47, 73867396.

10 J. Lee, S. B. Jo, M. Kim, H. G. Kim, J. Shin, H. Kim and K. Cho, Adv. Mater., 2014, 26, 6662.

11 J. Hou, Z. A. Tan, Y. Yan, Y. He, C. Yang and Y. Li, J. Am. Chem. Soc., 2006, 128, 4911-4916.

12 R. Duan, L. Ye, X. Guo, Y. Huang, P. Wang, S. Zhang, J. Zhang, L. Huo and J. Hou, Macromolecules, 2012, 45, 3032-3038.

13 C.-Y. Hsiow, R. Raja, C.-Y. Wang, Y.-H. Lin, Y.-W. Yang, Y.-J. Hsieh, S.-P. Rwei, W.-Y. Chiu, C.-I. Huang and L. Wang, Phys. Chem. Chem. Phys., 2014, 16, 25111-25120.

14 X. Liu, Y. Huang, Z. Cao, C. Weng, H. Chen and S. Tan, Polym. Chem., 2013, 4, 4737-4745.

15 C. Wang, B. Zhao, Z. Cao, P. Shen, Z. Tan, X. Li and S. Tan, Chem. Commun., 2013, 49, 3857-3859.

16 C.-Y. Kuo, W. Nie, H. Tsai, H.-J. Yen, A. D. Mohite, G. Gupta, A. M. Dattelbaum, D. J. William, K. C. Cha, Y. Yang, L. Wang and H.-L. Wang, Macromolecules, 2014, 47, 1008-1020.

17 P.-L. T. Boudreault, A. Najari and M. Leclerc, Chem. Mater., 2010, 23, 456-469.

18 Y. Li, Acc. Chem. Res., 2012, 45, 723-733.

19 S. Zhang, Z.-G. Zhang and Y. Li, Adv. Polym. Technol., 2013, 32, E822-E831.
20 X. Meng, W. Zhang, Z. A. Tan, C. Du, C. Li, Z. Bo, Y. Li, X. Yang, M. Zhen, F. Jiang, J. Zheng, T. Wang, L. Jiang, C. Shu and C. Wang, Chem. Commun., 2012, 48, 425-427.

21 K.-Y. Jen, M. Maxifield, L. W. Shacklette and R. L. Elsenbaumer, J. Chem. Soc., Chem. Commun., 1987, 309-311.

22 F. Goldoni, R. A. J. Janssen and E. W. Meijer, J. Polym. Sci., Part A: Polym. Chem., 1999, 37, 4629-4639.

23 J. Hou, Z. A. Tan, Y. He, C. Yang and Y. Li, Macromolecules, 2006, 39, 4657-4662.

24 Y. Qin and M. A. Hillmyer, Macromolecules, 2009, 42, 64296432.

25 Z. Zhang and Y. Qin, Macromolecules, 2016, 49, 3318-3327. 26 C.-J. Lin, W.-Y. Lee, C. Lu, H.-W. Lin and W.-C. Chen, Macromolecules, 2011, 44, 9565-9573.

27 Y. Liu, C.-C. Chen, Z. Hong, J. Gao, Y. Yang, H. Zhou, L. Dou, G. Li and Y. Yang, Sci. Rep., 2013, 3, 3356.

28 M. Xu, M. Zhang, M. Pastore, R. Li, F. De Angelis and P. Wang, Chem. Sci., 2012, 3, 976-983.

29 J. Hou, L. Huo, C. He, C. Yang and Y. Li, Macromolecules, 2006, 39, 594-603.

30 M. Zhang, F. Wu, Z. Cao, T. Shen, H. Chen, X. Li and S. Tan, Polym. Chem., 2014, 5, 4054-4060.

31 J. Hou, C. Yang, C. He and Y. Li, Chem. Commun., 2006, 871-873.

32 H. Tan, X. Deng, J. Yu, B. Zhao, Y. Wang, Y. Liu, W. Zhu, $\mathrm{H}$. Wu and Y. Cao, Macromolecules, 2012, 46, 113-118.

33 B. Burkhart, P. P. Khlyabich, T. Cakir Canak, T. W. LaJoie and B. C. Thompson, Macromolecules, 2011, 44, 1242-1246.

34 Z. He, C. Zhong, X. Huang, W.-Y. Wong, H. Wu, L. Chen, S. Su and Y. Cao, Adv. Mater., 2011, 23, 4636-4643.

35 R. C. Coffin, J. Peet, J. Rogers and G. C. Bazan, Nat. Chem., 2009, 1, 657-661.

36 P. P. Khlyabich, B. Burkhart, C. F. Ng and B. C. Thompson, Macromolecules, 2011, 44, 5079-5084.

37 B. Carsten, F. He, H. J. Son, T. Xu and L. Yu, Chem. Rev., 2011, 111, 1493-1528.

38 Z. Zhu, D. Waller, R. Gaudiana, M. Morana, D. Mühlbacher, M. Scharber and C. Brabec, Macromolecules, 2007, 40, 19811986.

39 U. Holzwarth and N. Gibson, Nat. Nanotechnol., 2011, 6, 534. 40 X. Zhang, L. J. Richter, D. M. DeLongchamp, R. J. Kline, M. R. Hammond, I. McCulloch, M. Heeney, R. S. Ashraf, J. N. Smith, T. D. Anthopoulos, B. Schroeder, Y. H. Geerts, D. A. Fischer and M. F. Toney, J. Am. Chem. Soc., 2011, 133, 15073-15084.

41 H.-L. Yip and A. K. Y. Jen, Energy Environ. Sci., 2012, 5, 59946011.

42 J.-M. Jiang, M.-C. Yuan, K. Dinakaran, A. Hariharan and K.-H. Wei, J. Mater. Chem. A, 2013, 1, 4415-4422.

43 Y.-M. Chang, W.-F. Su and L. Wang, Sol. Energy Mater. Sol. Cells, 2008, 92, 761-765.

44 C. Piliego, T. W. Holcombe, J. D. Douglas, C. H. Woo, P. M. Beaujuge and J. M. J. Fréchet, J. Am. Chem. Soc., 2010, 132, 7595-7597.

45 J. W. Jo, J. W. Jung, E. H. Jung, H. Ahn, T. J. Shin and W. H. Jo, Energy Environ. Sci., 2015, 8, 2427-2434. 
46 Y.-M. Chang, L. Wang and W.-F. Su, Org. Electron., 2008, 9, 968-973.

47 M.-C. Yuan, M.-Y. Chiu, C.-M. Chiang and K.-H. Wei, Macromolecules, 2010, 43, 6270-6277.

48 Y.-J. Cheng, S.-H. Yang and C.-S. Hsu, Chem. Rev., 2009, 109, 5868-5923.

49 B. C. Thompson and J. M. J. Fréchet, Angew. Chem., Int. Ed., 2008, 47, 58-77.

50 H. J. Son, F. He, B. Carsten and L. Yu, J. Mater. Chem., 2011, 21, 18934-18945.

51 H.-W. Liu, D.-Y. Chang, W.-Y. Chiu, S.-P. Rwei and L. Wang, J. Mater. Chem., 2012, 22, 15586-15591.

52 P. P. Khlyabich, B. Burkhart, A. E. Rudenko and B. C. Thompson, Polymer, 2013, 54, 5267-5298.

53 X. Chen, B. Liu, Y. Zou, W. Tang, Y. Li and D. Xiao, RSC Adv., 2012, 2, 7439-7448.

54 S. Günes, H. Neugebauer and N. S. Sariciftci, Chem. Rev., 2007, 107, 1324-1338.
55 N. Li, B. E. Lassiter, R. R. Lunt, G. Wei and S. R. Forrest, Appl. Phys. Lett., 2009, 94, 023307.

56 F. Liu, Y. Gu, X. Shen, S. Ferdous, H.-W. Wang and T. P. Russell, Prog. Polym. Sci., 2013, 38, 1990-2052.

57 J. Wang, M. Xiao, W. Chen, M. Qiu, Z. Du, W. Zhu, S. Wen, N. Wang and R. Yang, Macromolecules, 2014, 47, 7823-7830.

58 J.-M. Jiang, P. Raghunath, H.-K. Lin, Y.-C. Lin, M. C. Lin and K.-H. Wei, Macromolecules, 2014, 47, 7070-7080.

59 C.-Y. Kuo, Y.-C. Huang, C.-Y. Hsiow, Y.-W. Yang, C.-I. Huang, S.-P. Rwei, H.-L. Wang and L. Wang, Macromolecules, 2013, 46, 5985-5997.

60 A. F. M. Kilbinger and W. J. Feast, J. Mater. Chem., 2000, 10, 1777-1784.

61 R. S. Kularatne, F. J. Taenzler, H. D. Magurudeniya, J. Du, J. W. Murphy, E. E. Sheina, B. E. Gnade, M. C. Biewer and M. C. Stefan, J. Mater. Chem. A, 2013, 1, 15535-15543.

62 D. M. Robinson, Y. B. Go, M. Greenblatt and G. C. Dismukes, J. Am. Chem. Soc., 2010, 132, 11467-11469. 